\title{
SKIING WITH CEREBRAL PALSIED CHILDREN EXPERIENCES IN SWITZERLAND
}

\author{
ELSBETH KÖNG. M.D.*
}

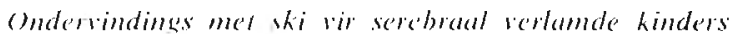
in Suriserland word beskryf. Probleme wat kinders mel spesificke gebrehe ondervind, word beklemtoon, asook die oplossings wat aan die lig gekom hel. Ontspamming is die belangrikste aspeh en iredering ('n prestasies word anamehaal.

* Head of Department. University Center for Cerebral Motor Disturbances, Berne. Switzerland.
Sport has become the main recreational activity of the youth of today. It is therefore psychologically important that the cerebral palsied child can also take part in sports aclivilies.

In Switzerland. skiing is a national sport. Earlier cercbral palsicd children tried to ski but gave up again because they could not compete with other children. Could they be helped by a special way of instruction? Fortunatels the Swiss Association for Sport 
of the Handicapped gave their support to it.

The first ski-week was held in 1966. Twelve schoolchildren, from 8 to 16 years old, with different slight handicaps, were selected. They all had to be able to walk freely and easily in spite of an abnormal movement pattern; to stand on one leg for a short time; to get up easily from the floor and to change from one side-sitting position to the other. Normal intelligence was required. (These conditions have remained the same ever since.) A ski-instructor was in charge of the technical programme, assisted by 4 neurodevelopmentally trained (NDT) therapists who were also good skiers. Accommodation was in a wonderful old chalet in the mountains. A house-mother (herself an experienced and enthusiastic leader of handicapped scouts), a cook and a volunteer completed the staff.

The first hours with the children on skis were rather discouraging; the abnormal movements became much more pronounced under the stress. Some children could hardly move on skis. They fell all the time. Some could not get up alone. This made us realize that the thildren needed to be well prepared by dry ski-school exercises. Therapists and ski-instructor worked out a scheme of exercises to overcome the difficulties, such as different grades of knee-bending in a downhill position, rotation movements from trunk and hips ("twist movements"), getting up from the floor with imaginary skis on the feet, weight-transfers, arms and legs swinging etc. Every morning started with the dry ski-school, with music and singing. After breakfast, this was followed by exercises with skis in the snow, on level ground, for instance knee-bending, parallel stick planting (to familiarize the children with their sticks; hemiplegics had to be urged from the beginning to use both sticks otherwise the associated reactions on the hemiplegic side increased), alternate ski-sliding on the spot, staying on one leg, swinging the other, jumping with legs parallel and lifting posterior skiends only, edging the skis to the left and to the right (to prevent slipping on uneven ground and as important preparation for side-stepping and traversing), then walking on skis with a good rhythm and changing directions.

Trying to ski downhill, the wrong movement patterns again became accentuated:

The spastic diplegics blocked themselves immediately in stem-position (stiff inward rotation of the legs, corresponding to their walking pattern) or, if they succeeded in keeping their skis parallel, they remained in a stiff flexor position with no ability to adapt to the terrain.

The hemiplegics, weight-bearing on their non-hemiplegic side, could not help being turned towards their handicapped side.

The athetoids had great difficulty in keeping their skis parallel, in using the edges of the skis, and, in particular, the intermittent extensor spasms of the whole body made adaptation to the terrain very difficult; they tended to fall backwards on shoulders and head. Others had the tendency to fix themselves in the stem-position, like the spastics.

The araxics needed to concentrate very hard not to lose direction; they fixed themselves broad-based and stiffly in flexion, and a change of direction was impossible.

These observations made us decide that the children should learn to ski without slem. Of course they were thrilled to start immediately to learn the parallel technique, which they knew so well from pictures and movies, and they co-operated with great enthusiasm. The ski-lessons did not differ very much from the ones for non-handicapped children, except that each child had to be helped individually to overcome his special difficulties. And it is essential that there are adequate periods of rest between the various exercises, because cerebral palsied children get tired more quickly and then their patterns deteriorate.

The progression in the ski-technique was: skiing downhill in a natural loose position, with and without sticks, at first with broad base, then skiing downhill combined with balance training (lifting up one ski repeatedly or jumping with the posterior ski-ends only), then traversing the first christiania towards the slope out of a traverse.

The results after only one week of skiing were most encouraging. All children were able to ski down a small slope and climb up again by side-stepping, and when they fell, were able to get up without help. Some of them were proud of their first christianias. The happy community life of the camp was a new experience for most of the children. It was wonderful to see how they grew more like a family during the week. Not only did they play games, sing and laugh together, but they also understood and helped each other more and more.

This first experience in 1966 was most encouraging. Since then, more than 60 ski-weeks have been held in different parts of the country, generally 5 a year, about 200 children taking part each winter. The results are better than we had ever hoped. The risk of accidents is no higher than with non-handicapped children.

Good team-work between NDT therapists and skiinstructors has proved essential. The ski-instructor should be experienced in teaching children. He requires to know something of the abnormal movement patterns and how to influence them, in order to avoid asking either too much or too little from the children. The therapists should orientate him to the problems of the individual children.

Dry ski-school and ski-exercises in the snow are the bridge between therapy and skiing. With these exercises the children get the feeling, i.e. the sensorimotor experience, of the basic movements of skiing. At the same time, they obtain warming-up and loosening of the muscles and better mobility. The beginners need a lot of therapeutic preparation. Even in the advanced group continuation of this preparation, though less intensive, is still necessary, with more adaptation to rhythm and speed. The children need to feel the correct downhill and raverse position so that it can be automatized and integrated.

It is also important to introduce games of all sorts in the programme of instruction, for instance objects can be put down and taken up during ski-runs, the children can ski through gates formed by sticks, there can be competitions or relay-races; in other words, the child's natural need for play must be taken into account.

As far as ski-technique is concerned the raverse has to be taught and repeated more often with cerebral palsied children as it is more difficult to get the right weight distribution. From good traversing, sideslipping and turning towards the slope can be developed easily. Turns are always practised towards both sides, whether it is a unilateral or bilateral handicap.

For several years it was a problem to find a way to teach the turn away from the slope. In the ordinary ski-technique, this turn is primarily initiated by stemming. But stemming in cerebral palsied children leads to fixation in abnormal movement patterns with reduction of mobility. This was solved by using the step turn, in traversing, by planting the stick downhill and simultaneously bending and turning the legs, with weight transfer from the inner to the outer ski. Practising in this way, the children often did a siem christiania, automatically without getting fixed in the stem position. 
They do many transitional turns ranging from the stem christiania to the step turn. Only later will they master parallel turns.

After 12 years we have found that many of the slightly handicapped cerebral palsied children can enjoy easy downhill runs. Quite a number of them are able to master runs of medium difficulty, even longer ones and a few manage to ski in deep snow. They can ski with their family and with non-handicaped companions. The better ones are helpers at our ski-weeks. Others less gifted for downhill skiing, have been taught and enjoy cross-country skiing.

To achieve this, more training, will-power and endurance is needed than in non-handicapped children, but the results are well-worthwhile for those who take pleasure in skiing. 